\title{
Hacia la Guerra Del Chaco. La legación de Chile en Asunción del Paraguay
}

\section{Towards The War of Chaco. The legation of Chile in Asunción del Paraguay}

\author{
Gabriela Dalla-Corte Caballero* \\ Taller de Estudios e Investigaciones Andino-Amazónicos \\ Universitat de Barcelona
}

(España)

dallacorte@ub.edu

\begin{abstract}
Resumen
Este artículo analiza el periodo que va de la Guerra del Pacífico (1879-1883) a la Guerra del Chaco (19321935), durante el cual Bolivia pierde la salida al mar, y Paraguay consolida su presencia en el territorio del Chaco Boreal. Se abordan los debates diplomáticos entre Chile y Argentina sobre la oferta de becas a oficiales paraguayos al acabar la Primera Guerra Mundial. Los organismos analizados corresponden a la Legación de Chile en Asunción (LChP), representada por los encargados Enrique Gallardo Nieto y Gonzalo Montt Rivas, y la Legación de Paraguay en Santiago de Chile (LPCh), dirigida por Fulgencio R. Moreno. La documentación se conserva en el Archivo General Histórico (AGHRE) del Ministerio de Relaciones Exteriores de la República de Chile (MRECH).
\end{abstract}

Palabras clave: Bolivia - Paraguay - Chile - Guerras - Relaciones Internacionales

DALLA-CORTE CABALLERO, Gabriela, "Hacia la Guerra del Chaco. La legación de Chile en Asunción del Paraguay”, en Avances del Cesor, Año XI, No 11, segundo semestre de 2014, pp. 19-40.

\footnotetext{
"Este trabajo se inscribe en el proyecto del Ministerio de Economía y Competitividad HAR2012-34095, desarrollado en el seno del TEIAA, Taller de Estudios e Investigaciones Andino-Amazónicos (2009SGR1400), grupo de investigación consolidado por el Comissionat per a Universitats i Recerca del DIUE de la Generalitat de Catalunya, España.
} 


\section{Abstract}

This article looks at the period from the Pacific War (1879-1883) to the Chaco War (1932-1935), during which Bolivia lost access to the sea, and Paraguay consolidated its presence in the territory of the Chaco Boreal. Diplomatic discussions between Chile and Argentina on the offer of scholarships to Paraguayan officials at the end of the First World War are discussed. The organisms under analysis correspond to the Legación de Chile en Asuncion (LCHP), represented by managers Enrique Nieto Gallardo and Gonzalo Montt Rivas, and the Legación de Paraguay en Santiago de Chile (LPCH), led by Fulgencio R. Moreno. The documentation is preserved in the Historical Archives (AGHRE) of the Ministry of Foreign Affairs of the Republic of Chile (MRECH).

Key Words: Bolivia - Paraguay - Chile - Wars - International Relations

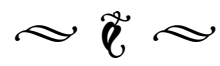

\section{Introducción}

Acabada la Guerra de la Triple Alianza -conflicto bélico de los años 1865 a 1870 que los aliados prefirieron denominar Guerra del Paraguay-, ${ }^{1}$ la República del Paraguay se incorporó al capitalismo mundial a través de la novedosa producción taninera, gracias a la explotación del rico árbol del quebracho de la zona del Chaco Boreal, ${ }^{2}$ que desde entonces acompañó a la histórica (y vigente) exportación yerbatera.

Bolivia, por su parte, se volcó a la lucha por ese rico territorio chaqueño después de ser derrotada durante la Guerra del Pacífico, conflicto bélico también denominado Guerra del Guano y Salitre. Dicho conflicto armado

1. BREZZO, Liliana M., "La guerra de la Triple Alianza en los límites de la ortodoxia: mitos y tabúes", en Revista Universum, Universidad de Talca, 2004, № 19, V. I, pp. 10-27

2. DALLA-CORTE CABALLERO, Gabriela, Lealtades firmes. Redes de sociabilidad y empresas. La Carlos Casado S.A. entre Argentina y el Chaco Paraguayo, CSIC, Madrid, 2009. acontecido entre 1879 y 1883, provocó el enfrentamiento entre Bolivia y Perú contra Chile, gracias al cual el gobierno chileno se apropió de la provincia de Arica. ${ }^{3}$

A partir de los primeros años del siglo XX le tocó el turno al conflicto diplomático boliviano-paraguayo por el control de la zona boreal del Gran Chaco latinoamericano, el cual desembocó en la guerra terrible desatada en 1932 y que llegó a su fin el 10 de junio de $1935 .^{4}$

En este caso concreto, fue Paraguay el que venció a Bolivia para controlar hasta el día de hoy las tierras chaqueñas.

Precisamente a inicios del siglo XX, Para-

3. SCAVONE YEGROS, Ricardo, Las relaciones entre el Paraguay y Bolivia en el siglo XIX, Servilibro, Asunción, 2004.

4. DALLA-CORTE CABALLERO, Gabriela, $L a$ Guerra del Chaco. Ciudadanía, Estado y Nación en el siglo $X X$. La crónica fotográfica de Carlos de Sanctis, Prohistoria Ediciones-TEIAA, Rosario, 2010 (libro reeditado por Editorial Intercontinental, Asunción del Paraguay, 2010). 
guay organizó su ejército para reducir la dependencia y el sometimiento impuestos por la República Argentina, y para garantizar su triunfo sobre Bolivia. En el año 1913 el ejército paraguayo recibió a una misión militar alemana destinada a reforzar la organización del cuerpo de sus oficiales. Esta misión se retiró de Asunción al año siguiente, precisamente al estallar la Primera Guerra Mundial. Es importante señalar que a mediados de 1915, y como respuesta a esta guerra internacional y a los propios resultados de conflicto territorial con Bolivia, ${ }^{5}$ el gobierno paraguayo dio a luz una Ley Orgánica Militar que dio inicio a la formación de sus oficiales en la República del Paraguay.

A partir de 1919, el ejército alemán dejó de ser visto como un instrumento idóneo para educar a los soldados paraguayos, y el gobierno del Paraguay optó por recrear sus vínculos con los Estados Unidos. El gobierno estadounidense facilitó al Paraguay la adquisición de dos destructores de guerra llamados "destroyers", que estaban predestinados a acompañar a los buques de combate. $^{6}$

Ese momento histórico acompañó el debate sobre una posible guerra que podía desatarse entre Paraguay y Bolivia por el control del espacio chaqueño, ${ }^{7}$ y por ello las autoridades

5. SCAVONE YEGROS, Ricardo, y BREZZO, Liliana M., Historia de las Relaciones Internacionales del Paraguay, E1 Lector, Asunción, 2010.

6. Archivo General Histórico (en adelante, AGHRE) del Ministerio de Relaciones Exteriores de la República de Chile (en adelante, MRECH), ficha 1.252, V. 841, de 01-01-1920 a 01-01-1921, Sección Clave telegramas cambiados entre MRECH y LChP.

7. DALLA-CORTE CABALLERO, Gabriela, "E1 Sudeste boliviano: los proyectos empresariales extranjeros en el Chaco boliviano-paraguayo (1880-1940)", en Revista militares paraguayas decidieron fomentar las relaciones con la República de Chile otorgando becas de formación a los oficiales paraguayos en Santiago de Chile.

El gobierno chileno decidió enviar a Asunción del Paraguay al Encargado de Negocios Enrique Gallardo Nieto. ${ }^{8}$ Era necesario también contrarrestar el impulso ofrecido por el embajador argentino en Paraguay, José María Cantilo. ${ }^{9}$ Esta pericia de carácter diplomático formaba parte, precisamente, de la organización de las Legaciones establecidas en el territorio rioplatense en construcción, en el cual la República del Paraguay jugaba un rol esencial. $^{10}$

Este artículo está dedicado precisamente a la reorganización del ejército paraguayo que había sido abatido durante la Gran Guerra (1865-1870). El periodo elegido va del fin de la Primera Guerra Mundial a los primeros años de la década de 1920, un momento crucial en el que se reorganizó el ejército paraguayo, y en el que el gobierno chileno jugó un importante papel a través de su Legación y de sus Encargados de Negocios establecidos en Asunción del Paraguay. La discusión sobre el rol de las becas argentinas y chilenas para fomentar la educación de los oficiales paraguayos

Tiempos de América, Castellón, 2007, V. 14, pp. 71-87, Universidad Jaume I.

8. AGHRE, ficha 1.281, V. 860, de 07-01-1921 a 3112-1921, O.C. 16 de LChP (Enrique Gallardo Nieto), Asunción, a MRECH, 3 de agosto de 1921, reproduce la carta de José Luis Larraín, Palma Chica, a Gallardo Nieto, Asunción, 16 de julio de 1921.

9. CANTILO, José María (hijo), Canciller Cantilo: la diplomacia al servicio de la paz, Perrot, Buenos Aires, 2007.

10. WARREN, Harris Gaylord, La reconstrucción del Paraguay, 1878-1904, Intercontinental Editora, Asunción, 2010. 
en Santiago de Chile y en Buenos Aires nos permite observar la presencia de los representantes chilenos en Asunción, a sabiendas de que su país había sido el vencedor de la Guerra del Pacífico, en oposición a Bolivia y Perú.

Para abordar la diplomacia de Chile en Asunción en la etapa previa al estallido de la Guerra del Chaco entre Bolivia y Paraguay, utilizamos la documentación conservada en el Archivo General Histórico (AGHRE) del Ministerio de Relaciones Exteriores de la República de Chile (MRECH). La mencionada documentación nos permite analizar los oficios confidenciales (O.C.) redactados por la Legación de Chile en Paraguay (LChP), así como los que elaboró la Legación de Paraguay en Chile (LPCh). Es importante señalar que la sigla MRECH sintetiza las diversas denominaciones que recibió el organismo chileno, y que fueron las siguientes: Ministerio de Relaciones Exteriores, Culto y Colonización (1888-1924); Ministerio de Relaciones Exteriores (1924-1930); Ministerio de Relaciones Exteriores y Comercio (1930-1941); Ministerio de Relaciones Exteriores de la República de Chile (desde 1941, MRECH).

Como es posible observar en este trabajo, entre los encargados de negocios chilenos establecidos en Asunción, mencionamos a Enrique Gallardo Nieto y a Gonzalo Montt Rivas. El segundo sustituyó al primero en el año 1922, y mostró coincidencias y discrepancias ideológicas acerca de la situación militar y económica paraguaya. Utilizó para ello las páginas de los informes confidenciales enviados al MRECH. Sobre esta base, en el primer apartado se analizan los informes confidenciales enviados a Santiago de Chile por Enrique Gallardo Nieto como responsable de la Legación de Chile en Asunción. En el segundo apartado se describe la incorporación de armas europeas en la República del Paraguay en el periodo de entreguerras. En el tercer apartado se examina la organización diplomática y militar paraguaya en el marco del proyecto internacional a favor de la extracción del petróleo del Chaco Paraguayo. En este caso se analizan los oficios confidenciales elaborados por Gonzalo Montt Rivas. Finalmente, en la conclusión se plantea la importancia de abordar la documentación diplomática de países supuestamente no vinculados a los conflictos bélicos.

\section{Paraguay y su ejército: los informes del chileno Gallardo Nieto}

Hasta el año 1919, la evolución militar paraguaya había sido lenta en virtud de los sacrificios hechos en el campo de lucha durante la Guerra de la Triple Alianza. El conflicto bélico redujo especialmente la población masculina. La resurrección paraguaya a la vida institucional de carácter nacional después de violentos cataclismos, exigía curar las heridas, una de las cuales era, sin duda, la formación de un orden militar que dejara atrás los supuestos extravíos políticos.

Fue precisamente en ese año, cuando el gobierno chileno decidió fortalecer su representación diplomática en el Paraguay, designando para ello a Enrique Gallardo Nieto. Tras instalarse en Asunción, Gallardo Nieto solicitó numerosas becas a su gobierno para promocionar la formación de los oficiales del ejército asunceño, y para contrastar el dominio que ejercía el Ministerio de Defensa argentino. Estas becas chilenas, según él, debían abandonar el carácter de "concesión", y adoptar 
el de "obligación", con la finalidad exclusiva de que el ámbito militar chileno pudiese competir contra la Escuela Militar de Buenos Aires. Tengamos en cuenta que la Guerra del Chaco fue el primer conflicto internacional americano en el que los ejércitos boliviano y paraguayo utilizaron aviones para el combate... por ello, era imprescindible, también, estrechar los vínculos de "tradicional amistad" entre Chile y la República del Paraguay, en especial en un momento crucial de definición de las relaciones internacionales después de concluida la Guerra del Pacífico. ${ }^{11}$

De acuerdo a los datos ofrecidos por la Legación de Chile en Paraguay, la primera reacción de Eusebio Ayala, por entonces Ministro de Relaciones Exteriores y Hacienda de Paraguay, ${ }^{12}$ fue obtener más datos acerca de las relaciones militares, económicas y políticas entre los gobiernos de Chile y de la República de la Altiplanicie, es decir, Bolivia. Ayala se mostró interesado especialmente en el contenido del protocolo confidencial que esos dos gobiernos andinos habían firmado en el año $1917 .{ }^{13}$

Presionado por el ministro Eusebio Ayala, el chileno Enrique Gallardo Nieto advirtió a su MRECH de que en Paraguay se aceptaba la presencia chilena frente a los países que conformaron la Triple Alianza, es decir, Argenti-

11. AGHRE, ficha 1.251 , V. 840, de 18-02-1919 a 3012-1920, O.C. 18 de LChP (Enrique Gallardo Nieto), Asunción, a MRECH, Santiago, 23 de abril de 1920

12. MORA, Frank O., La politica exterior del Paraguay (1811-1989), Centro Paraguayo de Estudios Sociológicos, Asunción, 1993.

13. AGHRE, ficha 1.171, V. 782 de 09-01-1919 a 3112-1919, O.C. 1 de LChP (Enrique Gallardo Nieto), Asunción, a MRECH, 25 de marzo de 1919. na, Brasil y Uruguay. ${ }^{14}$ Pero también agregó que, por entonces, predominaba el grupo contrario a la República de Chile, y liderado por el representante paraguayo en París: Cecilio Báez. ${ }^{15}$ Según Gallardo Nieto, del Ministerio de Relaciones Exteriores argentino salían con bastante frecuencia diversas noticias telegráficas destinadas a dañar la presencia chilena en Paraguay, hecho que se sumaba a una hiriente prensa paraguaya que prefería apoyar a la $\mathrm{Ar}$ gentina frente a Chile. ${ }^{16}$

Tengamos en cuenta que estos debates se produjeron en un momento crucial a nivel internacional: el fin de la Primera Guerra Mundial. Por ello, Gallardo Nieto apoyaba la formación del ejército paraguayo en Santiago de Chile, asegurando así la presencia chilena en Asunción en el caso de que el ejército llevase adelante una guerra contra Bolivia para garantizar sus posesiones chaqueñas.

En el año 1919, el ministro Eusebio Ayala aceptó enviar a un buen número de oficiales militares a la Argentina, gracias a la efectiva gestión realizada por el embajador argentino en Paraguay, José María Cantilo. Cuatro jóvenes se formaron en la Escuela Naval de Mecánicos; dos en la Escuela de Tiro de Infantería;

14. GARCÍA PÉREZ, Antonio, Reseña histórico-militar de la campaña de Paraguay (1864-1870), Capitán de Infantería, alumno en prácticas de la Escuela Superior de Guerra, en colaboración, Agapito Diez y Cía., Burgos, 1900 (colaboración de Rafael Rosendo Howard Arrién).

15. BREZZO, Liliana M. (estudio crítico); SCAVONE YEGROS, Ricardo y SCAVONE YEGROS, Sebastián (compiladores), Cecilio Báez - Juan E. O'Leary: polémica sobre la bistoria del Paraguay, Editorial Tiempo de Historia, Asunción, 2008.

16. AGHRE, ficha 1.171, V. 782 de 09-01-1919 a 3112-1919, O.C. 13 de LChP (Enrique Gallardo Nieto), Asunción, a MRECH, 17 de setiembre de 1919, "Propaganda de prensa". 
uno en la Escuela de Tiro de Artillería; otro en la Escuela de Caballería; y dos más en la Escuela Militar de Aviación del Palomar, que fueron el sargento Francisco Cusmanich, así como Victorio Barbero, el ex comisario de policía. En esa lucha absorbente -traducida en presiones de todo género-, el Encargado de Negocios chileno, Gallardo Nieto, incluyó en sus informes enviados a Santiago de Chile la tensa situación que vivía el ejército paraguayo. ${ }^{17}$ Según él, dicho ejército estaba dividido en dos corrientes perfectamente identificadas: una que consideraba que el ejército debía ser una institución netamente nacional, ajena a toda maquinación política y que tomara las bases de la educación del ejército chileno; y otra corriente liderada por el general de brigada Patricio Escobar, la cual valoraba el recurso armado como un medio para servir en situaciones políticas. ${ }^{18}$

Según Gallardo Nieto, Patricio Escobar había sido educado en el Colegio Militar de Buenos Aires hasta alcanzar el grado de te-

17. AGHRE, ficha 1.251 , V. 840, de 18-02-1919 a 3012-1920, O.C. 2 de LChP (Enrique Gallardo Nieto), Asunción, a MRECH, Santiago, "Contratación de una Misión Militar en Chile”, 6 de enero de 1919. AGHRE, ficha 1.281, V. 860, de 07-01-1921 a 31-12-1921, O.C. 10 de LChP (Enrique Gallardo Nieto), Asunción, a MRECH, 5 de abril de 1921, y O.C. 11 del 16 de abril de 1921. AGHRE, ficha 1.281, V. 860, de 07-01-1921 a 31-12-1921, O.C. 14 de LChP (Enrique Gallardo Nieto), Asunción, a MRECH, 5 de julio de 1921. AGHRE, ficha 1.317, V. 891, de 04-01-1921 a 31-12-1921, Telegrama 21 de LChP (Enrique Gallardo Nieto), Asunción, a MRECH, 6 de agosto de 1921.

18. AGHRE, ficha 1.258, V. 843 A, O.C. 22, Enviados y recibidos de los Ministerios, Intendencias y otros de Chile, de 14-04-1920 a 23-11-1921, LChP (ministro plenipotenciario de Chile en Paraguay Enrique Gallardo Nieto) a MRECH, Asunción, 4 de setiembre de 1921, refrendado por el Estado Mayor General del Ministerio de Guerra en Santiago de Chile. niente, y promocionaba el envío de diversos oficiales para ser instruidos por el ejército argentino que él consideraba como "uno de los mejores del mundo". Citando la memoria anual que Escobar había escrito un año antes, en 1918, como inspector general del ejército, Gallardo Nieto advirtió que el paraguayo estaba estrechamente vinculado al coronel Alberto de Noailles, por entonces agregado militar argentino en Asunción. ${ }^{19}$

Sin embargo, un interesante número de oficiales paraguayos siguieron camino abierto por las becas ofrecidas por el Encargado de Negocios Enrique Gallardo Nieto, muy interesado en formar a los oficiales paraguayos en diversos institutos militares chilenos. Nos referimos a Adolfo Chirife, Manlio Schenoni Lugo y Manuel Rojas.

Apenas llegado a Asunción en calidad de Encargado de Negocios de la Legación chilena en Paraguay, Gallardo Nieto se reunió con esos tres coroneles, quienes le manifestaron que era difícil reparar el pasado que habían sufrido en virtud de los países más poderosos, Brasil y Argentina, los cuales ejercían una influencia absorbente al comportarse como vencedores en la Guerra Grande (1865-1870). Tengamos en cuenta que hasta entonces los únicos adic-

19. AGHRE, ficha 1.171, V. 782, de 09-01-1919 a 3112-1919, O.C. 2 de LChP (Enrique Gallardo Nieto), Asunción, a MRECH, 28 de marzo de 1919. AGHRE, ficha 1.171, V. 782, de 09-01-1919 a 31-12-1919, anexos a O.C. 7, Copia de la carta del canciller argentino José María Cantilo al ministro de relaciones exteriores Eusebio Ayala, 29 de abril de 1919, y contestación de Eusebio Ayala del 2 de mayo de 1919. AGHRE, ficha 1.171, V. 782, de 09-01-1919 a 31-12-1919, O.C. 7 de LChP (Enrique Gallardo Nieto), Asunción, a MRECH, 24 de mayo de 1919. AGHRE, ficha 1.171, V. 782, de 09-01-1919 a 31-12-1919, O.C. 17 de LChP (Enrique Gallardo Nieto), Asunción, a MRECH, 23 de diciembre de 1919, "A estudiar aviación en Argentina". 
tos militares establecidos en Paraguay provenían de Argentina y de Brasil, así como de la propia España. El término "adicto" deriva del latín "addictus", y hace referencia a la persona dedicada y/o inclinada que se agrega para atender en algún asunto o desempeñar algún cargo o Ministerio. El término "adicto militar" se utiliza ante un miembro del ejército que se encuentra apegado al caso o a la situación.

En virtud de esta situación, Gallardo Nieto se contactó con el director de la Escuela Militar del Paraguay, Manlio Schenoni Lugo, la escuela que había sido inaugurada en el año 1916, en plena Guerra Mundial, y en la que el gobierno pretendía formar a la oficialidad paraguaya. Adolfo Chirife, por su parte, se había formado en la Escuela Militar de Santiago de Chile, fue teniente del ejército chileno, en su país natal se desempeñó como coronel, y llegó a ser ministro de Guerra del Paraguay desde 1920. Es comprensible que, pese al insistente ofrecimiento del ejército argentino para recibir a oficiales paraguayos y formarlos en diversos ámbitos militares, Chirife prefirió enviar a Santiago a un buen número de oficiales a su cargo. ${ }^{20}$ Manuel Rojas, finalmente, fue el jefe de Paraguarí, la zona militar más importante del país por la cercanía con Asunción, por su peso ante la frontera con Brasil, y en contacto con Pirayú, Yaguarón, Carapeguà, Escobar y Acahay. Como afirmara Ricardo Scavone Yegros, el levantamiento de los oficiales paraguayos se dio en las zonas militares a incitación de los schaeristas. ${ }^{21}$ Se trataba del territorio

20. AGHRE, ficha 1.251 , V. 840, de 18-02-1919 a 3012-1920, O.C. 12 de LChP (Enrique Gallardo Nieto), Asunción, a MRECH, Santiago, "Becas para el ejército del Paraguay”, 28 de marzo de 1920.

21. SCAVONE YEGROS, Ricardo, "Guerra Internacional y confrontaciones políticas (1920-1954)”, en TELESCA, Ignacio (coordinador), Historia del Paraguay, que a partir de 1854 -durante el gobierno de Carlos Antonio López- se vio beneficiado con la aceptación de la construcción del ferrocarril que sería inaugurado en 1861, y que a partir de 1870 extendió sus vías hasta Villarica y generó la fundación de importantes ciudades como Cerro León, Escobar, Sapucái y Caballero. ${ }^{22}$

De acuerdo a los representantes chilenos en Paraguay, la República de Chile era uno de los únicos países de la América del Sur que no había participado en la Guerra de la Triple Alianza, ${ }^{23}$ y que podía contribuir con sus conocimientos militares para la formación del ejército paraguayo en contra de Bolivia. ${ }^{24}$ Además, el conocimiento sobre el Chaco y sobre las pretensiones paraguayas y bolivianas era escaso en los propios ámbitos diplomáticos que se habían instalado en Asunción al compás de la Legación chilena. ${ }^{25}$

Es importante señalar que a finales de la década de 1910, la novedosa Escuela Militar paraguaya inaugurada en 1915 carecía de la infraestructura de que gozaban los países vecinos:

Taurus, Asunción, 2010, pp. 225-264.

22. AGHRE, ficha 1.281, V. 860, de 07-01-1921 a 3112-1921, O.C. 7 de LChP (Enrique Gallardo Nieto), Asunción, a MRECH, "Escuela Militar del Paraguay", 20 de marzo de 1921.

23. MAGNATERRA, Oscar Juan, La Guerra de la Triple Alianza: desde la diplomacia del Patacón al lenguaje del cañón, Editorial Dunken, Buenos Aires, 2002.

24. AGHRE, ficha 1.171, V. 782, de 09-01-1919 a 3112-1919, O.C. 15 de LChP (Enrique Gallardo Nieto), Asunción, a MRECH, 19 de diciembre de 1919, "Situación interna, la lucha internacional".

25. AGHRE, ficha 1.171, V. 782, de 09-01-1919 a 3112-1919, O.C. 6 de LChP (Enrique Gallardo Nieto), Asunción, a MRECH, "Sobre una solicitud de la Sociedad Peruana de Derecho Internacional de Lima”, 29 de abril de 1919. 
no reunía condiciones higiénicas; faltaban los gabinetes de física, química, armas portátiles, fortificación, sala de esgrima, polígono de tiro, campo de maniobras, material de artillería, dotación de caballos y mulas, telégrafos eléctricos y ópticos, teléfono de campaña y material de minas. La biblioteca sólo conservaba unos 500 volúmenes no especializados en temas militares... A la pobreza de recursos se sumaba un vestuario insuficiente y en mal estado, y los alumnos disponían de un único abrigo para los días lluviosos de invierno, y otro para el verano. Los alumnos ingresantes no pasaban un examen de ingreso que en otros países servía para seleccionar a los aspirantes. Habían ingresado jóvenes sin más estudios que el cuarto grado de formación primaria, y las materias eran más bien humanísticas que científicas. La sociedad civil no conceptuaba favorablemente al ejército, mientras los políticos rechazaban el mejoramiento de la carrera militar. Eso perjudicaba especialmente a los proyectos de educación de los jefes y de los oficiales, los cuales habían sido diseñados por la Escuela Militar. El chileno Gallardo Nieto comprobó que buena parte de los ingresantes como cadetes eran:

...Jóvenes sin padre, otros hijos naturales, y respecto a la conducta me han informado de varios casos de alumnos incorregibles que han ingresado por influencias políticas de sus padres para su doma y corrección en la Escuela, habiéndose hecho eco de ello la prensa de oposición y aun algún diario de los afectos al Gobierno. Respecto a la condición de nacimiento ya indicada, tal vez pudiera hallarse aquí justificación o excusa por haberse dado el caso, no hace muchos años, de haber un Ministro de Guerra y Marina que llevaba solamente el apellido de la madre. ${ }^{26}$

26. AGHRE, ficha 1.281 , V. 860, de 07-01-1921 a 31-
El representante chileno en Paraguay advirtió más de una vez sobre la disputa desplegada entre los países vecinos para hacerse con la formación de la oficialidad paraguaya. Ante el posible incumplimiento del propio gobierno paraguayo de enviar a Santiago de Chile a sus oficiales becados por La Moneda, Gallardo Nieto reprodujo en sus informes las quejas que levantó el oficial Manlio Schenoni en Asunción. En efecto, Schenoni clamó por la generosidad chilena para poder escapar de las garras argentinas en cuanto a la formación de los oficiales paraguayos. El propio Schenoni le había hecho llegar a Gallardo Nieto una carta reafirmando la necesidad de que los oficiales paraguayos fuesen formados en las Escuelas Militares y Navales chilenas, con la esperanza de que los estudiantes normales también pudiesen acceder en el futuro a las Facultades de Derecho, Medicina e Ingeniería de Chile. Como quedara en las páginas escritas por $\mathrm{Ga}-$ llardo Nieto, y enviadas a La Moneda, hasta entonces los médicos, ingenieros, abogados y profesores normales paraguayos se habían formado en centros de instrucción argentinos, ya que ese país había dado grandes facilidades para controlar a los hombres que desempeñarían en el futuro un rol nacional e internacional. En los hechos, Chile debía otorgar importantes facilidades a los paraguayos que quisieran instalarse temporalmente en Santiago de Chile para recibir una formación en el ejército.

De esta interpretación vino también la afirmación de Gallardo Nieto de que el adicto militar argentino establecido en Asunción, el Coronel Ângel de Hernández, había impul-

12-1921, O.C. 7 de LChP (Enrique Gallardo Nieto), Asunción, a MRECH, "Escuela Militar del Paraguay", 20 de marzo de 1921. 
sado activamente un proyecto similar que se implantó varios años antes de la declaración formal de la guerra desatada entre Bolivia y Paraguay por el Chaco Boreal. Coincidiendo con Schenoni, el chileno Gallardo Nieto concluyó entonces en sus informes que si la finalidad era frenar la dependencia paraguaya respecto a la República Argentina, el ejército paraguayo necesitaba que el gobierno chileno cumpliese con las becas ofrecidas. Las palabras de Schenoni que llegaron a Gallardo Nieto, fueron reproducidas por este último en su informe elevado al MRECH, y fueron las siguientes:

...Establecer una corriente de estrechamiento...que en el Paraguay se tengan ideas americanas no importadas únicamente del ambiente argentino, ambiente de cosmopolitas; queremos formar el criterio de nuestra juventud en forma independiente y libre de prejuicios que despide el ambiente argentino, para juzgar los hechos de nuestra historia y sobre todo para no empañar la justicia de nuestra causa nacional, en nuestra guerra traída no solamente por la infamia coaligada de los que destrozaron nuestra nacionalidad, nuestras y nuestro pueblo... el aislamiento de Uds. en el Plata se debe al abandono completo de su diplomacia por estos lados y a la actividad argentina que no escatima medios de conquistarse la gratitud, que nace de los favores dispensados por ella a manos llenas. Es, pues, necesario equilibrar esta influencia, y ese equilibrio no podría resultar sino del empleo de idénticas o más perfeccionadas armas políticas. ${ }^{27}$

27, AGHRE, ficha 1.171, V. 782, de 09-01-1919 a 3112-1919, O.C. 9 de LChP (Enrique Gallardo Nieto), Asunción, a MRECH, 28 de agosto de 1919, "Becas al Ejército del Paraguay".

\section{El fin de la Primera Guerra Mundial: las armas europeas hacia la República del Paraguay}

Al llegar a su fin la Primera Guerra Mundial, observamos los preparativos del gobierno peruano para recuperar Tacna y Arica; las aspiraciones de Bolivia para recuperar la salida al mar, utilizando proyectiles especiales; la propaganda boliviana y peruana contra Chile; el agravamiento de la cuestión de límites entre Paraguay y Bolivia; la instrucción militar de oficiales paraguayos becados por el gobierno chileno; la contratación de instructores chilenos para el ejército paraguayo; así como el aumento de los presupuestos paraguayos para gastos de defensa y de contratación de instructores chilenos para sustentar al ejército. ${ }^{28}$

Algunos periódicos asunceños acompañaron este proceso, y el responsable de la Legación de Chile en Paraguay reprodujo en su informe dos textos concretos y opositores entre sí: el diario llamado Patria, contrario a la dependencia respecto a la República Argentina, junto a la prensa El Liberal, vinculada a la presencia argentina en Paraguay. Patria, por ejemplo, puntualizó que no era admisible someterse al tutelaje vecinal de Argentina y de Brasil, ya que Paraguay podía revivir el dolor de la derrota y la imposición del vencedor; en síntesis, pensar en Argentina suponía aceptar la subordinación al poder del Río de la Plata. El diario llamado El Liberal, en cambio, se manifestó a favor de la formación de su oficialidad en la Argentina para llevar adelante la entonces definida "cuestión del Chaco". Ambos pe-

28. AGHRE, ficha 1.281, V. 860, de 07-01-1921 a 3112-1921, O.C. 21 de LChP (Enrique Gallardo Nieto), Asunción, a MRECH, 4 de setiembre de 1921. 
riódicos, sin embargo, se mostraron partidarios de la educación de los "elementos nacionales" para nutrir y mejorar las instituciones armadas, y, en especial, para responder a la presión boliviana que podía desembocar en la Guerra del Chaco. ${ }^{29}$ Así lo observó la Legación de Chile en Asunción, y así fue presentada al MRECH $y$, en consecuencia, a La Moneda.

Por entonces, Enrique Gallardo Nieto creía que Paraguay era un país inmerso en la fase organizativa, tanto política como económica y militar, y cuya democracia era casi nominal. De acuerdo a este representante chileno, era imprescindible incrementar la política interna para eliminar las facciones. En efecto, la lucha entre los "colorados" y los "radicales" (también "azules") era una cuestión más bien "personal", en palabras de Gallardo Nieto. Esa lucha estaba unida desde 1921 al fraccionamiento de los "liberales", ${ }^{30}$ es decir, entre jóvenes universitarios "gondristas" -ligados al político Manuel Gondra Pereira, nacido en Buenos Aires, representante consular paraguayo en Washington y presidente del Paraguay en 1910-1911 y 1920-1921-, así como "schaeristas" seguidores del presidente del Paraguay en 1912-1916, Eduardo Schaerer Vera y Aragón, el cual apoyaba al coronel Adolfo Chirife. ${ }^{31}$

29. Los textos periodísticos mencionados que llegaron a Santiago de Chile corresponden a: AGHRE, ficha 1.251, V. 840, de 18-02-1919 a 30-12-1920, “ ¿Somos independientes o no?”, Patria, Asunción, 06/01/1920. AGHRE, ficha 1.251, V. 840, de 18-02-1919 a 30-12-1920, "Misión extranjera”, El Liberal, Asunción, 30/12/1919; “Misión Militar", 03/01/1920; "Nuestras relaciones internacionales", 06/01/1920.

30. CARRÓN, Juan M., MONTE DE LÓPEZ MOREIRA, María G., AYALA, Anselmo, GIMÉNEZ, Salvadora, El régimen liberal, 1870-1930. Sociedad, economía y cultura, Arandurà Editorial, Asunción, 2005.

31. AGHRE, ficha 1.251 , V. 840, de 18-02-1919 a 3012-1920, O.C. 1 de LChP (Enrique Gallardo Nieto),
Como ha afirmado Ricardo Scavone Yegros en sus excelentes trabajos dedicados precisamente a la diplomacia, el sector gondrista (guggiarista) del radicalismo, interesado en reforzar el orden liberal, encontraría un gran rechazo entre los colorados que a partir de la Revolución de 1936 adoptarían una nueva Constitución y reforzarían las Fuerzas Armadas como factor determinante de poder. ${ }^{32}$

Por cuestiones de espacio, y por organización política, las reuniones del Senado y de la Cámara se hacían por entonces en un único salón de sesiones, y en días alternos. Siguiendo esta norma de organización política, el grupo de Gondra apoyó al por entonces Ministro de Relaciones Exteriores y Hacienda, Eusebio Ayala, un hombre más que vinculado a las empresas extranjeras radicadas en el Chaco Paraguayo, $y$ adherente a la presencia argentina en Paraguay. ${ }^{33}$

Asunción, a MRECH, Santiago, "Entrevista con el Ministro de Relaciones Exteriores Ramón Lara Castro", 27 de diciembre de 1919. AGHRE, ficha 1.251, V. 840, de 18-02-1919 a 30-12-1920, O.C. 2 de LChP (Enrique Gallardo Nieto), Asunción, a MRECH, Santiago, 24 de enero de 1920.

32. SCAVONE YEGROS, Ricardo, "Guerra Internacional y confrontaciones políticas (1920-1954)”, en TELESCA, Ignacio (coordinador), Historia ..., Op. Cit., pp. 225-264.

33. AGHRE, ficha 1.171, V. 782, de 09-01-1919 a 31-12-1919, O.C. 11 de LChP (Enrique Gallardo Nieto), Asunción, a MRECH, 2 de setiembre de 1919, "Renuncia del Ministro del Interior". AGHRE, ficha 1.171, V. 782, de 09-01-1919 a 31-12-1919, O.C. 10 de LChP (Enrique Gallardo Nieto), Asunción, a MRECH, 2 de setiembre de 1919. AGHRE, ficha 1.281, V. 860, de 07-01-1921 a 31-12-1921, O.C. 6 de LChP (Enrique Gallardo Nieto), Asunción, a MRECH, 4 de marzo de 1921. AGHRE, ficha 1.281, V. 860, de 07-01-1921 a 31-12-1921, O.C. 9 de LChP (Enrique Gallardo Nieto), Asunción, a MRECH, "Sobre el mensaje presidencial 
También existían dos grupos con marcadas tendencias dentro del ejército: uno llamado "Círculo Militar", el cual carecía de domicilio legal, era dirigido por Patricio Alejandrino Escobar-el único general del país-, y estaba conformado por jefes y oficiales procedentes, en su mayoría, de la revolución producida en el año 1904. El otro grupo estaba constituido por los coroneles que habían sido becados y formados en Chile, incluyendo algunos jefes y oficiales que no eran partidarios del "caudillismo militar", así como a los 36 jóvenes oficiales que habían egresado de la Escuela Militar desde el año 1917. Esta división dentro del ejército también se reflejaba entre los 54 cadetes que estudiaban en esa Escuela Militar porteña, así definida la escuela militar argentina por $\mathrm{Ga}^{-}$ llardo Nieto. La procedencia familiar, económica y territorial de los tenientes paraguayos también se reflejaba en las discusiones y en los conflictos surgidos en esos años al compás del reforzamiento del ejército. En palabras de $\mathrm{Ga}-$ llardo Nieto, y de acuerdo al informe confidencial que hizo llegar a las oficinas del MRECH, donde la unidad de procedencia es un hecho, no existen disputas ni divisiones:

No es una reunión de hombres con aptitudes y preparación suficientes para llenar los altos cometidos que en los actuales tiempos y en los ejércitos nacionales competen a los militares, ni dejan de darse cuenta de que el jefe A, o el oficial B, a pesar de su completa falta de aptitud, son mantenidos en filas por la única razón de que contribuyeron con su sangre a elevar al poder al gobierno y al Partido Radical. Manifiéstase más esta

de Manuel Gondra", 3 de abril de 1921. AGHRE, ficha 1.341, V. 909, de 06-01-1922 a 12-12-1922, O.C. 1 de LChP (Gonzalo Montt Rivas, Encargado de Negocios de Chile en Paraguay), a MRECH, "Política Interna del Paraguay", 25 de marzo de 1922. penetración al ser promovidos a segundos tenientes y al prestar su servicio en las zonas y unidades militares, en las que se pone de manifiesto palpablemente la división, que lleva aparejada consigo las rencillas, los odios y hasta los atropellos e injusticias que no existen allí donde la unidad de procedencia es un hecho. ${ }^{34}$

En el momento en que se implementó este proyecto presentado por la Legación de Chile en Asunción, Santiago de Chile recibió cinco oficiales. E1 Ministerio de Guerra, así como el director de la Escuela Militar, el coronel Manlio Schenoni Lugo, se guiaban por la reputación de la formación militar chilena, en la que intervenían instructores del ejército imperial alemán de gran calificación. Como afirmara Gallardo Nieto en uno de sus tantos informes confidenciales, Schenoni Lugo llegó a plantear al teniente coronel Hernández, el adicto militar argentino, la ilegitimidad de enviar oficiales paraguayos a estudiar a Buenos Aires, ya que por entonces los argentinos siempre celebraban las efemérides en honor al desastroso resultado de la Guerra del Paraguay. Esta actitud del ejército argentino resultaba mortificante para los oficiales paraguayos que tenían que presenciarla durante los años de su formación en la capital del país vecino.

El coronel Schenoni también hizo referencia a la insistente oferta de baterías de campaña que hizo el gobierno francés al gobierno paraguayo. Francia colaboró con la "Casa Schneider Cannet" para asegurar su supervivencia, pero también se volcó a la exportación de sus armas hacia Asunción del Paraguay. Frente a

34. AGHRE, ficha 1.281 , V. 860, de 07-01-1921 a 31-12-1921, O.C. 25 de LChP (Enrique Gallardo Nieto), Asunción, a MRECH, "La Escuela Militar del Paraguay", 6 de setiembre de 1921. 
esta situación, Manlio Schenoni Lugo propuso enviar a sus oficiales al extranjero, en este caso a Chile, antes que comprar armas al ejército francés.

Es importante señalar que en esos años de posguerra, Alemania nombró a un enviado extraordinario y ministro plenipotenciario, a un cónsul de carrera, y a un canciller, con el mandato de que se instalasen en la República del Paraguay. Italia, por su parte, trasladó a Asunción a un enviado extraordinario y ministro plenipotenciario, dejando el Consulado en manos de un funcionario de carrera. Las Legaciones de España, Gran Bretaña y Francia, finalmente, fueron representadas por un encargado de negocios y un cónsul de carrera.

Los países americanos, por su parte, acreditaron una significativa representación consular y diplomática. Argentina estaba representada por un enviado extraordinario y ministro plenipotenciario, un adicto militar, un cónsul general, un cónsul de carrera, dos vice-cónsules y un canciller. La Legación de Bolivia estaba a cargo de un ministro plenipotenciario, dos secretarios y un adicto militar con el grado de coronel, además de un cónsul general y un vice-cónsul. Cuba mantenía un encargado de negocios y un cónsul. Los Estados Unidos estaban representados por un ministro plenipotenciario, un secretario, un canciller, un cónsul general y un vice-cónsul de carrera. Perú, con un enviado extraordinario y ministro plenipotenciario, un secretario y cónsul de carrera. Uruguay legitimó la presencia de un ministro plenipotenciario, dos secretarios, un cónsul general y un vice-cónsul de carrera. El resto de países americanos sólo mantenían agentes consulares con funciones puramente comerciales. ${ }^{35}$

Fue el momento en que, más allá de las propuestas formuladas por los ejércitos y ministerios de relaciones exteriores argentino y chileno, un buen número de cadetes paraguayos fueron establecidos desde inicios de la década de 1920 en Río de Janeiro. ${ }^{36}$ Asunción, paralelamente, recibió una representación consular de primera clase que fue liderada por el plenipotenciario brasileño José de Paula Rodríguez Alvez -que participaría activamente en la firma del Tratado de Paz al finalizar la Guerra del Chaco-, y por un adicto militar, ambos interesados en fomentar el envío de oficiales paraguayos a la capital brasilera, por entonces Río de Janeiro. Como vemos, la distribución territorial de los estudiantes paraguayos se hizo en el marco de la disputa económica y política que existía entre los gobiernos de Brasil y Argentina, ambos países interesados en obtener el apoyo paraguayo a nivel diplomático. ${ }^{37}$

35. AGHRE, ficha 1.401, V. 954, de 02-01-1923 a 27-12-1923, O.C. 6 de Legación de Chile en Paraguay (Gonzalo Montt Rivas), a MRECH, "Cuerpos diplomático y consular residentes”, 27 de agosto de 1923

36. AGHRE, ficha 1.281, V. 860, de 07-01-1921 a 3112-1921, O.C. 19 de LChP (Enrique Gallardo Nieto), Asunción, a MRECH, "Facilidades a oficiales paraguayos en Chile”, 25 de agosto de 1921. AGHRE, ficha 1.258, V. 843 A, O.C., enviados y recibidos de los Ministerios, Intendencias y otros de Chile, de 14-04-1920 a 2311-1921., O.C. 19, LChP (Enrique Gallardo Nieto) a MRECH, Asunción, 25 de agosto de 1921, refrendado por el Estado mayor General del Ministerio de Guerra en Santiago de Chile. AGHRE, ficha 1.281, V. 860, de 07-01-1921 a 31-12-1921, O.C. 22 de LChP (Enrique Gallardo Nieto), Asunción, a MRECH, “Sobre una oferta de armamentos", 4 de setiembre de 1921.

37. AGHRE, ficha 1.341, V. 909, de 06-01-1922 a 1212-1922, O.C. 5 de LChP (Gonzalo Montt Rivas, Encargado de Negocios de Chile en Paraguay), a MRECH, Anexo: "Artículo de prensa sobre ejército brasileño", 3 de 
La impresión de Manlio Schenoni Lugo ante esta transformación diplomática era más que trascendente, y en virtud de su condición de responsable de la adquisición de armamento para el ejército paraguayo. De hecho, fueron los poderes europeos los que empezaron a indagar en América Latina un mercado para las armas que habían sobrado durante la Primera Guerra Mundial. La casa "Schneider Cannet", con el apoyo del gobierno francés, ofreció sus sobrantes armamentos al gobierno paraguayo, y le otorgó grandes facilidades financieras. Esto transformó el proyecto del ejército del Paraguay (en gran parte ideado precisamente por Schenoni Lugo), ya que en un principio los fondos debían ser utilizados para la construcción de cuarteles y para enviar a sus oficiales al extranjero -en especial, Argentina, Chile, pero también Brasil-, con la finalidad de que aprendieran el manejo y el modo de limpiar y guardar los fusiles. ${ }^{38}$

Gallardo Nieto también hizo llegar al MRECH la información de que la cuestión de límites se encontraba sin resolución en vir-

mayo de 1922. AGHRE, ficha 1.341, V. 909, de 06-011922 a 12-12-1922, O.C. 2 de LChP (Gonzalo Montt Rivas, Encargado de Negocios de Chile en Paraguay), a MRECH, "Política exterior del Paraguay", 27 de marzo de 1922. AGHRE, ficha 1.401, V. 954, de 02-01-1923 a 27-12-1923, O.C. 5 de LChP (Gonzalo Montt Rivas), a MRECH, "E1 Ministro del Brasil en el Paraguay, delegado a la V.C.P.A.”, 10 de febrero de 1923

38. AGHRE, ficha 1.258, V. 843 A, O.C., enviados y recibidos de los Ministerios, Intendencias y otros de Chile, de 14-04-1920 a 23-11-1921, O.C. 22, LChP (Enrique Gallardo Nieto, Ministro Plenipotenciario de Chile en Paraguay) a MRECH, Asunción, 4 de setiembre de 1921, refrendado por el Estado Mayor General del Ministerio de Guerra en Santiago de Chile. AGHRE, ficha 1.251, V. 840, de 18-02-1919 a 30-12-1920, O.C. 2 de LChP (Enrique Gallardo Nieto), Asunción, a MRECH, 24 de enero de 1920. tud de la enorme presión ejercida por el $\mathrm{go}^{-}$ bierno argentino: el embajador argentino en Paraguay, José María Cantilo, por ejemplo, le había expresado durante un almuerzo que a su país no le convenía que Bolivia llegase a ser tributario del Río de la Plata. Según Cantilo, las pretensiones bolivianas de dominar el territorio del Chaco, que él definió con el nombre de "Paraguayo", llegaban casi hasta la capital, Asunción, ya que esta última se encontraba muy cerca del rio que les unía a "la apetecida salida al Atlántico". ${ }^{39}$

Desde inicios de 1920 Bolivia protestó contra el envío y la movilización de un buen número de soldados paraguayos al Estero Patiño. ${ }^{40}$ Esta región se ubica a $250 \mathrm{~km}$ de Asunción por vía fluvial, y sigue su curso por el río Pilcomayo, precisamente la frontera con Argentina -representada, por entonces, por el Territorio Nacional de Formosa, luego provincia-, límite que se estableció a finales del siglo XIX, después de la Guerra del Paraguay. ${ }^{41}$ En épocas lluviosas, esa zona servía $-y$ sirve- de cauce a los desbordes del Pilcomayo. Para el gobierno boliviano, se trataba de una región litigiosa establecida por el laudo llevado adelante por el ex presidente estadounidense

39. AGHRE, ficha 1.171, V. 782, de 09-01-1919 a 3112-1919, O.C. 20 de LChP (Enrique Gallardo Nieto), Asunción, a MRECH, 29 de diciembre de 1919, "Nuestros asuntos con Bolivia”.

40. AGHRE, ficha 1.317, V. 891, de 04-01-1921 a 3112-1921, Telegrama 12 de LChP (Enrique Gallardo Nieto), Asunción vía Legación de Buenos Aires, a MRECH, 21 de abril de 1921.

41. DALLA-CORTE CABALLERO, Gabriela, y VÁZQUEZ RECALDE, Fabricio, La conquista y ocupación de la frontera del Chaco entre Paraguay y Argentina. Los indígenas tobas y pilagás y el mundo religioso en la Misión Tacaaglé del Rio Pilcomayo (1900-1950), TEIIA, Publicacions de la Universitat de Barcelona, Barcelona, 2011. 
Rutherford B. Hayes, quien había fijado la línea divisoria sur del Chaco paraguayo en el brazo principal del río Pilcomayo, cuyo curso natural cruzaba una línea de zanjones al norte del Estero Patiño. Por ello, mientras Paraguay sostenía que la frontera estaba establecida en la zona del sur, el gobierno argentino afirmaba que el brazo principal estaba ubicado en la zona norte. ${ }^{42}$ Ante la demanda boliviana, el gobierno paraguayo se defendió al afirmar que sólo respetaba el protocolo del 12 de enero de 1907, por el que se había admitido el establecimiento de militares paraguayos en las zonas no litigiosas. ${ }^{43}$

La acumulación de tropas en la frontera con Argentina, así como la instalación de los "colonos extranjeros" en la zona disputada con Bolivia, formó parte de un acto poco amistoso: como reconocería Enrique Gallardo Nieto en uno de sus tantos informes confidenciales enviados a Santiago de Chile, la cuestión limítrofe paraguayo-boliviana coincidía con los propósitos del gobierno asunceño de entregar las tierras chaqueñas a los extranjeros, en particular a los europeos. Es importante resaltar que, por entonces, el gobierno paraguayo sólo controlaba el "Ferrocarril Central Paraguay" (FECP) que unía a la localidad de Posadas con las líneas argentinas en la zona fronteriza. $\mathrm{El}$ gobierno paraguayo aprovechó entonces la huelga organizada por los trabajadores de la “Compañía Argentina de Navegación Nicolás Mihanovich Limitada" producida en la capital argentina: se apoderó de algunos de sus barcos

42. AGHRE, ficha 1.281, V. 860, de 07-01-1921 a 3112-1921, O.C. 20 de LChP (Enrique Gallardo Nieto), Asunción, a MRECH, “Cuestión del Pilcomayo”, 28 de agosto de 1921.

43. AGHRE, ficha 1.317, V. 891, de 04-01-1921 a 31-12-1921, Telegrama 15 de LChP (Enrique Gallardo Nieto), Asunción, a MRECH, 28/29 de abril de 1921. y los entregó a capitanes y oficiales de la Marina de Guerra para cubrir la zona marítima entre Asunción y Corumbá, en disputa con Bolivia. Para el chileno Enrique Gallardo Nieto, era hora de reconocer que lo que ocurría en Argentina afectaba directamente al Paraguay; pero también que los obreros paraguayos seguían a los obreros argentinos:

Si el obrero resulta de alguna importancia aquí, es debido a que existe mucha unión entre la Federación Obrera del Paraguay y la de Argentina. Así ocurre que la huelga marítima destinada a boycotear a la Empresa Mihanovich y decretada en Buenos Aires, encuentra decisivos colaboradores en Asunción. Mihanovich envió hace días desde Montevideo a Asunción, con bandera uruguaya, al vapor Arapey, y en el acto los obreros marítimos argentinos telegrafiaron a los del Paraguay que se prepararan para no descargarlo, lo que ocurrió, viéndose el Gobierno necesitado a valerse de la marinería de guerra para tal operación... Por mucho que sufra la Argentina y por grandes que sean las pérdidas producidas por los paros o los boycotts, nunca podrán equipararse a las acciones de la misma índole en el medio tan reducido de este país (Paraguay). ${ }^{44}$

Fue el momento elegido por el representante chileno en Paraguay para aconsejar, 1lamativamente, a su propio MRECH, de que era necesario acrecentar el contacto diplomático con Bolivia para frenar de alguna manera

44. AGHRE, ficha 1.251, V. 840, de 18-02-1919 a 3012-1920, O.C. 2 de LChP (Enrique Gallardo Nieto), Asunción, a MRECH, Santiago, 24 de enero de 1920. También véase: AGHRE, ficha 1.251, V. 840, de 18-021919 a 30-12-1920, O.C. 14 de LChP (Enrique Gallardo Nieto), Asunción, a MRECH, Santiago, 2 de abril de 1920. AGHRE, ficha 1.281, V. 860, de 07-01-1921 a 31-12-1921, O.C. 8 de LChP (Enrique Gallardo Nieto), Asunción, a MRECH, 27 de marzo de 1921. 
el poderío de los colonizadores extranjeros en la tierra chaqueña, entre ellos la "Mihanovich". Una tierra que, por entonces, se encontraba en litigio y en disputa, y en el que el gobierno boliviano podía ejecutar mejores gestiones militares que las que había llevado adelante contra Chile durante la Guerra del Pacífico. La propuesta de este diplomático chileno radicado en Asunción no fue otra que establecer un contacto directo con la Legación chilena en $\mathrm{La} \mathrm{Paz}$, pero siempre vía MRECH. ${ }^{45}$

En los hechos, a finales de la Primera Guerra Mundial, la América del Sur se abocó al reforzamiento de sus vínculos diplomáticos internacionales y a la intensificación del conocimiento geográfico de espacios en los que todavía se mantenían intensas disputas que pudiesen derivar en un conflicto bélico. Por ello el chileno Gallardo Nieto se dispuso a iniciar un diálogo más fructífero entre ambos países. El "coloradista" paraguayo Fulgencio R. Moreno (1872-1933) hizo lo propio al asumir el cargo de ministro ante los gobiernos andinos representados por Chile, Bolivia y Perú, aceptando así la propuesta que le hizo el presidente liberal Manuel Gondra. ${ }^{46}$ Tengamos en cuenta que el conocimiento de Moreno sobre el Chaco Boreal en disputa entre Paraguay y Bolivia, le granjeó la confianza del gobierno de turno, y durante la Guerra del Chaco se desempeñó como miembro de la Comisión asesora de límites. ${ }^{47}$

45. AGHRE, ficha 1.281, V. 860, de 07-01-1921 a 3112-1921, O.C. 13 de LChP (Enrique Gallardo Nieto), Asunción, a MRECH, "Cuestión limítrofe paraguayo-boliviana”, 20 de abril de 1921.

46. AGHRE, ficha 1.171, V. 782, de 09-01-1919 a 3112-1919, O.C. 5 de LChP (Enrique Gallardo Nieto), Asunción, a MRECH, "Bolivia y sus salidas al Pacífico y al Atlántico”, 19 de abril de 1919.

47. MORENO, Fulgencio R., La extensión territorial del
Fulgencio R. Moreno llegó por primera vez a Santiago de Chile en 1918. Según sus palabras, su finalidad era hacerse cargo, nuevamente, de la Legación del Paraguay en Chile, de la que se había retirado temporalmente para establecerse en La Paz, y desempeñar la Plenipotencia Especial de la cuestión de límites con Bolivia. Ya en la capital boliviana, Fulgencio R. Moreno pidió al gobierno chileno el envío de un oficial especializado en instrucción en artillería para integrarse a Paraguay con el grado de capitán. ${ }^{48} \mathrm{Al}$ año siguiente, Gallardo Nieto comunicó a su canciller chileno que el paraguayo Moreno se encontraba, en realidad, en la ciudad de Asunción, y que El Liberal -el periódico matutino de carácter oficialista, por entonces dirigido por el senador Belisario Rivarola- había publicado parte de la entrevista que le hicieran al paraguayo, en la que este último afirmó que su país se había "mezclado" en la cuestión del Chaco contra Bolivia.

Fulgencio R. Moreno definió también el momento en que "explotó" este problema: fue cuando Bolivia observó la extensa zona con frente sobre el río Paraguay, en la que era posible fundar puertos y construir vías férreas que

Paraguay al occidente de su río. Breve exposición de los títulos paraguayos, Imprenta Nacional, Asunción, 1933

48. AGHRE, ficha 1.112, V. 728 A, de 02-01-1918 a 30-12-1918, Legación de Paraguay en Chile (LPCh) (Fulgencio R. Moreno), Santiago, a MRECH (Daniel Feliú Manterola), notas recibidas de la Misión Residente, 23 de abril de 1918. AGHRE, ficha 1.112, V. 728 A, de 02-01-1918 a 30-12-1918, Nota de Fulgencio R. Moreno, Legación de Paraguay en Chile (LPCh), La Paz, a MRECH (Daniel Feliú Manterola), Notas recibidas de la Misión Residente, 15 de junio de 1918. AGHRE, ficha 1.281, V. 860, de 07-01-1921 a 31-12-1921, O.C. 27 de LChP (Enrique Gallardo Nieto), Asunción, a MRECH, "Cuestión de límites boliviano-paraguaya", 22 de setiembre de 1921 
le permitiesen la comunicación con el estuario del Plata, y con los departamentos de Tarija y Chuquisaca. Por ello, consciente de la importancia del territorio chaqueño, Gallardo Nieto aprovechó el informe enviado a su canciller y afirmó que se trataba de un espacio prácticamente desconocido, despoblado, y que estaba comprendido entre los ríos Paraguay y Pilcomayo, hacia el paralelo 19030'. En su informe fue más concluyente al escribir que el canciller paraguayo Eusebio Ayala había efectuado un viaje por el Chaco con la finalidad de visitar los frigoríficos y las empresas tanineras, que en su gran mayoría contaban con una fuerte inversión norteamericana, observando la poca inteligencia boliviana al querer adueñarse de un territorio tan feroz como el chaqueño. Agregó que se trataba de un espacio inundable en época de lluvia, pero carente de agua durante las sequías en la que los exploradores estaban a menudo expuestos a perecer por la sed. ${ }^{49}$

\section{Montt Rivas y los vínculos diplomáticos y militares en pos del petróleo}

En 1922, Gallardo Nieto fue sustituido por Gonzalo Montt Rivas como Encargado de Negocios de Chile en Asunción. Fue él quien informó que, por entonces, el ejército paraguayo se componía de 1799 varones distribuidos

49. AGHRE, ficha 1.171 , V. 782, de 09-01-1919 a 3112-1919, Fulgencio R. Moreno, "Bolivia y su salida al mar. El Paraguay mezclado en la cuestión del Pacífico", El Liberal, Asunción, 18 de abril de 1919. AGHRE, ficha 1.171, V. 782, de 09-01-1919 a 31-12-1919, O.C. 5 de LChP (Enrique Gallardo Nieto), Asunción, a MRECH, "Bolivia y sus salidas al Pacífico y al Atlántico", 19 de abril de 1919. También véase AGHRE, ficha 1.171, V. 782, de 09-01-1919 a 31-12-1919, O.C. 15 de LChP (Enrique Gallardo Nieto), Asunción, a MRECH, 19 de diciembre de 1919, "Situación interna, la lucha internacional". en destacamentos y guarniciones, sin contar el personal de las oficinas militares dependientes del Ministerio de Guerra. Las zonas eran las siguientes: la primera, con asiento en Concepción y dirigida por el coronel Brizuela, que contaba con 136 hombres; la segunda, en Paraguarí, tenía 493 hombres a cargo del coronel Adolfo Chirife; la tercera, con asiento en Pilar, había sido suprimida; la cuarta, en Villa Rica, conservaba 515 a cargo del coronel Pedro Mendoza, que era el segundo de Chirife. En el Chaco, por su parte, existían los siguientes destacamentos: en el Chaco Austral había 44 hombres, 52 en el Chaco Norte, así como 52 gendarmes en la frontera de Vella Vista, Pedro Juan Caballero, San Carlos y Capitán Bado. Las guarniciones, por su parte, se distribuían entre Villa Hayes con 160 soldados que formaban la compañía de zapadores; así como 277 en Asunción, utilizados para la escolta presidencial, las ametralladoras y la compañía de infantería. En Misiones había unos 77 hombres en el escuadrón de caballería, y ese era el ejército paraguayo... ${ }^{50}$

Como es evidente, la mayor cantidad de fuerzas de los coroneles responsables de la segunda y cuarta zona decidía la política interna, situación que se produjo en junio de $1922 .{ }^{51}$ Por entonces el coronel Adolfo Chirife, a cargo de la zona del Paraguarí, pasaba en realidad la mayor parte del tiempo en Asunción para promocionar su candidatura como miembro

50. AGHRE, ficha 1.341, V. 909, de 06-01-1922 a 12-12-1922, La Marina de Guerra estaba formada por una escuela de grumetes, un buque escuela y arsenales; O.C. 2 de LChP (Gonzalo Montt Rivas, Encargado de Negocios de Chile en Paraguay), a MRECH, Anexo "Distribución de las fuerzas, ejército del Paraguay", 27 de marzo de 1922.

51. BREZZO, Liliana, El Paraguay a comienzos del siglo XX (1900-1932), Editorial El Lector, Asunción, 2010. 
del futuro gobierno nacional. Así lo expresó en sus informes el Encargado de Negocios Montt Rivas.

En los hechos, Adolfo Chirife se acantonó junto con el coronel Pedro Mendoza en dos zonas militares (segunda y tercera), y dieron apoyo al grupo "schaerista" que seguía a Eduardo Schaerer Vera y Aragón..$^{52}$ El gobierno paraguayo movilizó a los ciudadanos de 20 a 35 años para invadir las zonas acantonadas, y nombró al coronel Schenone como jefe al mando de 2.500 hombres. ${ }^{53}$

Adolfo Chirife, por su parte, trató de tomar por sorpresa la capital, pero sus fuerzas se retiraron tras seis horas de fuego intenso, 40 muertos y 150 heridos, datos que ofreció a La Moneda su responsable Montt Rivas. Para garantizar el futuro del presidente paraguayo, el decano argentino pidió la asistencia del buque "Rosario", el cual permaneció en la costa de la capital durante los días del ataque de los coroneles Adolfo Chirife y Pedro Mendoza ${ }^{54}$ (este último huyó posteriormente de Asunción, y se instaló en Buenos Aires con la esperanza de salvaguardar su vida). Al mismo tiempo, el gobierno paraguayo solicitó al gobierno argentino el urgente envío de armas, ${ }^{55}$ y con el

52. AGHRE, ficha 1.341, V. 909, de 06-01-1922 a 1212-1922, O.C. 7 de LChP (Gonzalo Montt Rivas, Encargado de Negocios de Chile en Paraguay), a MRECH, Anexo, 8 de mayo de 1922,

53. AGHRE, ficha 1.341, V. 909, de 02-01-1922 a 31-12-1922, Telegrama de LChP (Gonzalo Montt Rivas, Encargado de Negocios de Chile en Paraguay), a MRECH, 2 de junio de 1922.

54. AGHRE, ficha 1.341, V. 909, de 06-01-1922 a 1212-1922, O.C. 9 de LChP (Gonzalo Montt Rivas, Encargado de Negocios de Chile en Paraguay), a MRECH, “Revolución”, 3 de junio de 1922.

55. AGHRE, ficha 1.341, V. 909, de 06-01-1922 a 12- objetivo de frenar el avance independentista del ejército. ${ }^{56}$

En ese momento, todos los representantes se reunieron en sesión permanente para defender los intereses de "sus nacionales" ante este conflicto. El chileno Montt Rivas relató entonces el rol ejercido por el cuerpo diplomático ante la revolución ejercida por parte de un sector específico del ejército paraguayo:

Cada cual llegaba con noticias de la revolución, oídas en el tranvía o en la peluquería, y cada jefe de misión insinuaba que era indispensable tomar tal o cual determinación. Como mi casa se encontraba entre las trincheras y me era difícil llegar al centro, no corrían ni autos ni tranvías, y como nada sacaba en claro de las conversaciones de mis colegas, que generalmente degeneraban en cursos de derecho internacional público y privado, resolví no salir de la Legación. ${ }^{57}$

La resolución de este movimiento militar colocó a Eusebio Ayala en buena posición para las futuras elecciones nacionales. Adolfo Chirife se retiró a mediados de 1922, y las tropas de Paraguarí y Villa Rica abandonaron las zonas y se dirigieron a Encarnación, la localidad ubicada frente a la ciudad argentina de Posa-

12-1922, O.C. 12 de LChP (Gonzalo Montt Rivas, Encargado de Negocios de Chile en Paraguay), a MRECH, "El gobierno paraguayo solicita armas del argentino", 22 de junio de 1922.

56. AGHRE, ficha 1.341, V. 909, de 06-01-1922 a 1212-1922, O.C. 10 de LChP (Gonzalo Montt Rivas, Encargado de Negocios de Chile en Paraguay), a MRECH, “Revolución”, 19 de junio de 1922.

57. AGHRE, ficha 1.341, V. 909, de 06-01-1922 a 12-12-1922, O.C. 11 de LChP (Gonzalo Montt Rivas, Encargado de Negocios de Chile en Paraguay), a MRECH, "El cuerpo diplomático y la revolución", 15 de junio de 1922. 
das. ${ }^{58}$ El coronel Schenoni, por su parte, fue promovido a Ministro de Guerra y Marina en sustitución del coronel Manuel Rojas quien, además de encontrarse en ese momento en Alemania, era uno de los amigos más íntimos de Chirife. El coronel Schenoni, educado por el ejército chileno, decidió apoyar al gobierno cuando se produjo el levantamiento de Chirife en la campaña. Gonzalo Montt Rivas describió este singular caso paraguayo de la siguiente manera:

...El escalafón presentará entonces el raro caso de un ejército con dos generales y sin coroneles y tenientes coroneles, pues los jefes de este grado han sido dados de baja por su participación en el actual movimiento. No deja de llamar la atención esta falta de jefes en un país asolado por constantes revoluciones, que en otras Repúblicas traen entre otros males una serie larga de generales y coroneles. ${ }^{59}$

Según Montt Rivas, dicha situación marcaba un nuevo escalafón militar en función de su adhesión al presidente Eusebio Ayala. Ahora bien, la división se mantuvo durante muchos meses ya que Chirife era apoyado por los trabajadores de los yerbales y, en especial, por las familias que trabajaban en las estancias ganaderas fundadas en las zonas más lejanas de la capital que eran ricas en caballos. Pero

58. AGHRE, ficha 1.341, V. 909, de 06-01-1922 a 1212-1922, O.C. 14 de LChP (Gonzalo Montt Rivas, Encargado de Negocios de Chile en Paraguay), a MRECH, "Últimas noticias sobre la revolución", 14 de julio de 1922; y O.C. 16, "Sobre la revolución”, 17 de agosto de 1922. AGHRE, ficha 1.396, V. 952, de 01-01-1923 a 3112-1923, Telegrama de LChP (Vicecónsul Rafael Nieto), a MRECH, 19 de agosto de 1922.

59. AGHRE, ficha 1.341, V. 909, de 06-01-1922 a 1212-1922, O.C. 20 de LChP (Gonzalo Montt Rivas, Encargado de Negocios de Chile en Paraguay), a MRECH, 20 de noviembre de 1922 . para los dueños de las tierras ricas en ganado, en yerbales y en tanino del árbol del quebracho, la "revolución militar" de Chirife era acompañada de "montoneras", de trabajadores de los yerbales, de sátiros. ${ }^{60}$ Por ello, las frases utilizadas por Montt Rivas en las páginas del informe que envió al MRECH, lo distancian ideológicamente de Enrique Gallardo Nieto, precisamente el anterior Encargado de Negocios en la capital paraguaya:

... Casi todos los individuos que siguen a Chirife son trabajadores de los yerbales y de las estancias de esa zona, que, al incorporarse a la revolución, se han librado de los compromisos que tenían con sus patrones por deudas contraídas con las pulperías de los establecimientos, deudas que apenas amortizaban con años de trabajo. ${ }^{61}$

Uno de los casos más conocidos de la época se produjo en Puerto Pinasco, en la zona chaqueña volcada al río Paraguay, donde funcionaba una de las más importantes fábricas de tanino de la zona chaqueña, precisamente la empresa de Santiago Pinasco llamada "Compañía Rosarina de Campos y Bosques”. Allí se produjo un movimiento obrero que los empresarios calificaron de "bolchevista" y "subversivo", como consta en la documentación enviada a Santiago de Chile por la Legación establecida en Paraguay. Cerca de tres mil obreros se apoderaron de las oficinas y de los talleres con el pretexto de que el Comisario de Policía "no los trataba con justicia". Felizmente los

60. CABALLERO CAMPOS, Herib, "Bandidos y sátiros: dos casos en Paraguay (1920-1930)”, en Revista Páginas, Rosario, 2013, Año 5, No 9, pp. 91-109. Escuela de Historia, Universidad Nacional de Rosario (UNR),

61. AGHRE, ficha 1.401, V. 954, de 02-01-1923 a 27-12-1923, O.C. 2 de LChP (Gonzalo Montt Rivas), a MRECH, 21 de enero de 1923. 
trabajadores consiguieron llegar a un acuerdo con los responsables de la fábrica, los cuales les otorgaron el aumento de sus salarios, la reducción de las horas de trabajo, y la destitución del Comisario. Sin embargo, ese fue el momento en el que -por primera vez desde el fin de la Guerra de la Triple Alianza- el gobierno paraguayo impuso una medida de auténtico rigor entre los trabajadores: un juez de la capital ordenó la confiscación de los bienes de los principales "revolucionarios", a sabiendas de que el país carecía por entonces de leyes vigentes. ${ }^{62}$

Por ello, si bien el gobierno consideraba que las posibilidades de Chirife eran mínimas, su acción y la de más de dos mil soldados bajo su mando podían "anarquizar" al Paraguay. Para Montt Rivas, la guerra contra Bolivia era el único mecanismo de unión y de destrucción del "anarquismo" del ejército paraguayo. Pero también podía servir para frenar la movilización de los trabajadores que preferían una revolución frente a la economía nacional dominada por empresarios y hacendados, en su mayoría básicamente extranjeros:

Hasta hace pocos días se creía que la revolución estaba virtualmente terminada y que era cuestión de pocos meses el someter a los caudillos civiles que asolan la campaña con sus montoneras. Desgraciadamente no ha sido así. Chirife ha logrado enganchar bastante gente en el... rehaciendo su ejército, que pasa hoy de mil hombres, todos bien montados, pues ha requisicionado la caballada de esa zona, que es la mejor del país. El gobierno se ha visto obligado a enviar en su persecución diversos destacamentos, que en total suman cerca de dos mil soldados...

62. AGHRE, ficha 1.401, V. 954, de 02-01-1923 a 27-12-1923, O.C. 1 de LChP (Gonzalo Montt Rivas), a MRECH, "Revolución y servicios públicos", 20 de enero de 1923. creo que la revolución no tiene ya probabilidad alguna de éxito, pero puede continuar anarquizando el país por largo tiempo. Es casi imposible combatir a las montoneras en la zona de los yerbales y montes, tanto más cuanto que se trata de individuos que operan en su propio terreno. Casi todos los individuos que siguen a Chirife son trabajadores de los yerbales y de las estancias de esa zona, que al incorporarse a la revolución se han librado de los compromisos que tenían con sus patrones por deudas contraídas con las pulperías de los establecimientos, deudas que apenas amortizaban con años de trabajo. Es sumamente delicada la situación del momento, por lo que respecta a la economía nacional. ${ }^{63}$

Las conclusiones que presentó Montt Rivas en ese informe elevado a Santiago de Chile fueron las siguientes:

Las tropas revolucionarias han ganado acceso a las orillas del Alto Paraguay, ocupan ya algunos puertos y es de temer que por este motivo se paralice la navegación de ese río, lo que traería la paralización total, también, del comercio nacional. La revolución ha tomado un carácter enteramente personal, pues hoy día el coronel Chirife, y sus tropas, están desligadas de toda influencia política. Mucho se comenta el viaje de dos personajes políticos, amigos del presidente, que han ido a Buenos Aires, según se dice, a tratar con el coronel Mendoza, segundo de Chirife, la manera de poner término al conflicto. ${ }^{64}$

63. AGHRE, ficha 1.401, V. 954, de 02-01-1923 a 27-12-1923, O.C. 1 de LChP (Gonzalo Montt Rivas), a MRECH, "Revolución y servicios públicos", 20 de enero de 1923.

64. AGHRE, ficha 1.401, V. 954, de 02-01-1923 a 27-12-1923, O.C. 1 de LChP (Gonzalo Montt Rivas), a MRECH, "Revolución y servicios públicos", 20 de enero de 1923. 
Es importante señalar que a inicios de la década de 1920, el paraguayo Fulgencio R. Moreno accedió a Bolivia como plenipotenciario. Tres años después, en enero de 1923, el diputado boliviano Arturo Alonso Quesada llegó a Asunción en calidad de Encargado de Negocios. Las ideas de este último eran conocidas entre los miembros del Congreso paraguayo, ya que se estaban divulgando los intensos debates sobre la cuestión petrolífera que, según el entonces diputado Arturo Alonso Quesada, eran la causa del futuro conflicto boliviano-paraguayo.

Para asumir su condición de Encargado de Negocios, Alonso Quesada efectuó un intenso viaje que comenzó en Cochabamba y siguió por Santa Cruz, Puerto Suárez, Corumbá, atravesando así la región petrolífera. Desde allí accedió a la zona chaqueña en litigio con el Paraguay, que también podía ser rica en petróleo, y lo hizo con las tropas que avanzaron con la intención de reconocer el territorio en el que podían llevar adelante la guerra contra Paraguay.

Como señalara Montt Rivas, la razón de la llegaba de Alonso Quesada al Paraguay no fue otra que "recorrer, por cuenta fiscal, la zona misma e imponerse de visu de sus riquezas". Agregó en su informe que Bolivia estaba interesada en solucionar el conflicto del Chaco ya que la "Standard Oil" había iniciado sus trabajos en las propiedades vecinas de Santa Cruz. Esta reconocida empresa necesitaba llegar al río Paraguay para embarcar el petróleo y exportarlo a los Estados Unidos. ${ }^{65}$

65. DALLA-CORTE CABALLERO, Gabriela, Empresas y tierras de Carlos Casado en el Chaco Paraguayo. Historias, negocios y guerras (1860-1940), Intercontinental Editora, Asunción, 2012.
El nuevo Encargado de Negocios boliviano, Alonso Quesada, intentó obtener facilidades para tender las cañerías hacia el puerto paraguayo de Bahía Negra, que se encontraba en la zona más próxima a los pozos. En caso de no llegar a un acuerdo con Paraguay, la segunda alternativa era negociar con el gobierno argentino la utilización del puerto de Formosa para establecer los depósitos y los puntos de embarque para la exportación. En ambos casos, Bolivia podía aprovechar la misma vía fluvial representada por el río Paraguay que desembocaba en el río Paraná. En estos términos, como afirmó Montt Rivas, la producción de la "Standard Oil" podía ser de gran utilidad para el propio Paraguay, pero sólo aportando ventajas y promoviendo los arreglos entre ambos países, y no sólo observando "las ventajas para sus propios intereses". ${ }^{66}$

En ese preciso momento, Eusebio Ayala, miembro del Partido Liberal, se mantuvo como presidente provisorio e impidió que Schaerer, el líder del Partido Colorado, asumiese a la presidencia a través de las elecciones ejecutadas en febrero de 1923. Eusebio Ayala fue reemplazado en el mes de abril por el entonces Ministro de Hacienda, Eligio Ayala, en diálogo directo con Buenos Aires. ${ }^{67}$ Para

66. AGHRE, ficha 1.401, V. 954, de 02-01-1923 a 27-12-1923, O.C. 5 de LChP (Gonzalo Montt Rivas), a MRECH, 24 de enero de 1923.

67. AGHRE, ficha 1.401, V. 954, de 02-01-1923 a 27-12-1923, O.C. 6 de LChP (Gonzalo Montt Rivas), a MRECH, "Informaciones generales", 1 de marzo de 1923. AGHRE, ficha 1.401, V. 954, de 02-01-1923 a 27-12-1923, O.C. 8 de LChP (Gonzalo Montt Rivas), a MRECH, "Informe político-revolución", 15 de abril de 1923. AGHRE, ficha 1.401, V. 954, de 02-01-1923 a 27-12-1923, O.C. 8 de LChP (Gonzalo Montt Rivas), a MRECH, "Informe sobre la revolución”, 27 de mayo de 1923. 
Montt Rivas, que en esto coincidía con su antecesor Gallardo Nieto, no existía duda alguna sobre la dependencia que por entonces sufría el Paraguay respecto a la República Argentina, en particular por el dominio que esta última ejercía en las vías férreas y en las líneas fluviales de vapores. Esta dependencia ocasionaba multitud de problemas ante el monopolio comercial y de tránsito en manos extranjeras, en particular el ejercido por la "Compañía Argentina de Navegación Nicolás Mihanovich Limitada". Los proyectos de formación y educación de los oficiales paraguayos en Chile no podían competir de manera alguna con las fuerzas económicas, políticas y comerciales implantadas por la República Argentina.

\section{Reflexiones finales}

El peso de la concesión de becas para los oficiales paraguayos formó parte del proceso de organización del ejército, el cual acompañó la reconstrucción económica y la expansión de la diplomacia paraguaya. Esta es la base de este artículo, interesado precisamente en describir la presencia diplomática chilena en Asunción del Paraguay, y las gestiones llevadas adelante por los Encargados de Negocios de la Legación de Chile, Gallardo Nieto y Montt Rivas.

Estos responsables formaron parte del proceso de organización diplomática y militar del Paraguay al acabar la Primera Guerra Mundial. Precisamente las negociaciones referidas a las becas argentinas y chilenas, fomentaron la educación de los grupos de oficiales paraguayos que residieron especialmente en Santiago de Chile y en Buenos Aires. No hay duda de que las becas ofrecidas por La Moneda a los oficiales paraguayos, fueron gestionadas por la
Legación chilena en Asunción. Los informes diplomáticos de los Encargados de Negocios, sin embargo, también exteriorizaron la unidad entre la política de cooperación del gobierno radical argentino en manos de Hipólito Yrigoyen (presidente en 1916-1922 y 1928-1930), y la de los liberales paraguayos.

La violencia y la represión son instancias constitutivas de la formación del Estado- $\mathrm{Na}$ ción, y conservan el rol de crear y mantener el sistema político. No se trata de una simple restricción de derechos y libertades, sino también la utilización del control social expresado en múltiples campos: psicológico, económico, familiar, étnico, ideológico, moral, político, y, por qué no, diplomático. Siguiendo el ejemplo argentino, la Dirección de Escuelas de Paraguay dio la orden de rememorar las fechas patrias de los países latinoamericanos cuya designación, a su vez, fue impuesta a las escuelas nacionales paraguayas. ${ }^{68}$ Era un proyecto de unidad latinoamericana de mayor envergadura que se produjo durante los debates fronterizos que todavía dividían a los países vecinos, en particular al Paraguay y a Bolivia.

El 30 de octubre de 1936 se reunió en Buenos Aires la Conferencia de Paz del Chaco cuyos delegados fueron Luis Barros Borgoño (Chile), Spruille Braden (Estados Unidos), José de Paula Rodríguez Alvez (Brasil), Eugenio Martínez Theady (Uruguay), Felipe Barreda Laos y Luis Fernán Cisneros (Perú), así como Ricardo Bunge y Carlos Saavedra Lamas (Argentina). Este último se había desempeñado, llamativamente, como abogado defensor de la empresa fundada en 1886 por el español

68. AGHRE, ficha 1.401, V. 954, de 02-01-1923 a 27-12-1923, O.C. 3 de LChP (Gonzalo Montt Rivas), a MRECH, 7 de junio de 1923. 
Carlos Casado del Alisal, la cual controlaba la zona chaqueña en la que se debatieron los ejércitos boliviano y paraguayo entre 1932 y 1935 . Durante la reunión reservada y presidida por el representante brasilero José de Paula Rodríguez Alvez (el mismo que había visitado la ciudad de Asunción en 1922...), se abordó la reglamentación de las funciones de vigilancia y control en el Chaco definido, precisamente, como "Paraguayo". ${ }^{69}$

En general se ha dejado de lado la actuación de la República de Chile en la organización del conflicto bélico iniciado en 1932. Han recibido mayor atención los históricos comisionados del siglo XIX, en particular franceses, ${ }^{70}$ estadounidenses ${ }^{71}$ y británicos, ${ }^{72}$ es decir, las mismas nacionalidades de los empresarios que se apoderaron del Chaco Paraguayo después de la Guerra de la Triple Alianza. La organización de la diplomacia paraguaya en Bolivia,

69. AGHRE, ficha 2.271, V. 1.551, de 30-10-1936 a 02-01-1937, Conferencia Interamericana de Paz del Chaco, Actas reservadas (90-112), Acta 90 del 30 de octubre de 1936, "Deliberación sobre gestiones referentes al nombramiento de la Comisión de reglamentación complementaria de la función de control y vigilancia en el Chaco".

70. Como ejemplo, véase: CAPDEVILA, Luc, y RODRÍGUEZ ALCALÁ, Guido, Nueva Burdeos. Colonización francesa en el Paraguay, Embajada de Francia, Asunción, 2005; CAPDEVILA, Luc, Una guerra total: Paraguay, 1864-1870. Ensayo de historia del tiempo presente, Centro de Estudios Antropológicos de la Universidad Católica-Buenos Aires, Ed. Sb, Asunción, 2010 (traducción de Ana Couchonnal).

71. Como ejemplo, véase: WHIGHAM, Thomas L., CASAL, Juan Manuel, La diplomacia estadounidense durante la Guerra de la Triple Alianza: escritos escogidos de Charles Ames Washburn sobre el Paraguay, 1861-1871, Editorial Servilibro, Asunción, 2008.

72. HERKEN KRAUER, Juan Carlos y GIMÉNEZ DE HERKEN, María Isabel, Gran Bretaña y la Guerra de la Triple Alianza, Editorial Arte Nuevo, Asunción, 1983. por ejemplo, ha sido especialmente analizada por Ricardo Scavone Yegros. ${ }^{73}$ En los hechos, la propuesta de enviar oficiales paraguayos a Chile, provino de la propia Legación chilena en Asunción, y fue aceptada formalmente por el emergente gobierno paraguayo. ${ }^{74}$

La documentación mencionada en este trabajo nos permite comprobar que la Legación de Chile establecida en Asunción del Paraguay, participó en este proceso histórico, $\mathrm{y}$ aportó interesantes informes confidenciales que hoy día nos pueden ofrecer datos alternativos a los que se diseñaron en las sedes de los Consulados europeos y estadounidense. $\mathrm{La}$ documentación del AGHRE del MRECH otorga una importante información acerca de los embajadores que representaban a Argentina y a Chile, en este caso ofreciendo becas de estudio para un ejército en construcción como fue, precisamente, el ejército paraguayo.

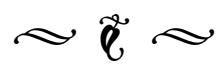

Recibido: $10 / 09 / 2013$ Aceptado: 05/03/2014

73. SCAVONE YEGROS, Ricardo, Benjamín Aceval, E1 Lector, Asunción, 2013.

74. BREZZO, Liliana M., "Reconstrucción, poder político y revoluciones (1870-1920)", en TELESCA, Ignacio (coordinador), Historia..., op. cit., pp. 199-224. 